\title{
Two 3D supramolecular frameworks assembled from the dinuclear building block: A crystallographic evidence of carboxylate $(O) \ldots \pi$ interaction
}

\author{
SUDIP MOHAPATRA $^{\mathrm{a}}$, SYAMANTAK ROY ${ }^{\mathrm{a}}$, DEBAJYOTI GHOSHAL ${ }^{\mathrm{b}}$ \\ and TAPAS KUMAR MAJI ${ }^{\mathrm{a}, *}$ \\ ${ }^{a}$ Molecular Materials Laboratory, Chemistry and Physics of Materials Unit, Jawaharlal Nehru Centre \\ for Advanced Scientific Research, Jakkur, Bangalore 560 064, India \\ ${ }^{b}$ Department of Chemistry, Jadavpur University, Jadavpur, Kolkata 700 032, India \\ e-mail: tmaji@jncasr.ac.in
}

MS received 9 January 2014; revised 9 April 2014; accepted 19 April 2014

\begin{abstract}
Two new complexes of $\mathrm{Mn}$ (II) and $\mathrm{Zn}$ (II) have been synthesized using a mixed ligand system and characterized by IR spectroscopy, elemental analysis, single crystal x-ray diffraction and variable temperature magnetic study for one of the compounds. Dimeric coordination structures of $\left[\mathrm{Mn}_{2}(2,4-\text { pyrdc })_{2}(\right.$ bpe $\left.)\left(\mathrm{H}_{2} \mathrm{O}\right)_{6}\right] \cdot 2 \mathrm{H}_{2} \mathrm{O}(\mathbf{1})$ and $\left[\mathrm{Zn}_{2}(2,4-\text { pyrdc })_{2}(\right.$ azpy $\left.)\left(\mathrm{H}_{2} \mathrm{O}\right)_{6}\right] \cdot 2 \mathrm{H}_{2} \mathrm{O}(2) \quad[2,4$-pyrdc $=2,4-$ pyridinedicarboxylate; bpe $=1,2$-bis(4-pyridyl)ethane; azpy $=4,4^{\prime}$ azopyridine] are constructed by the bridging of bpe and azpy, respectively and both are extended to a 3D supramolecular structure by non-covalent interactions. In both the cases, unprecedented carboxylate $(\mathrm{O}) \ldots \pi$ interactions played a crucial role in the organization of the 3D supramolecular assembly. The carboxylate $(\mathrm{O}) \ldots \pi$ interactions are controlled by the C-H. . $\pi$ interactions which were accomplished by the proper modulation of the organic linkers. The formation of these supramolecular frameworks revealed that control of weak interactions can be achieved by the interplay of both energetically strong (covalent) and weak forces (non-covalent).
\end{abstract}

Keywords. $\mathrm{Mn}(\mathrm{II})$ and $\mathrm{Zn}(\mathrm{II})$ complex; dinuclear complex; supramolecule; anion- $\pi$ interactions; antiferromagnetic interaction.

\section{Introduction}

The design and synthesis of metal-organic frameworks have grown as fields that have been explored rapidly and extensively over the last two decades. ${ }^{1-3}$ A wide range of polynuclear metal complexes or coordination polymers or supramolecular architectures with different dimensionalities (1D/2D/3D) have been discovered in recent years with novel structural topologies and interesting physical and chemical properties. ${ }^{4-7}$ But in spite of the extensive growth of this field with a massive database, there are still some lacunae on the understanding of some supramolecular forces, which play a significant role in building extended architectures. ${ }^{8-11}$ The anion- $\pi$ interactions are one such supramolecular forces. ${ }^{12-15}$

The importance of $\pi \ldots \pi$ interactions in biological systems, ${ }^{16}$ in particular its role in the stabilization of the DNA double helix structure has been well established. ${ }^{17}$ The cation- $\pi$ interactions are also found in nature, where they significantly contribute to the

\footnotetext{
*For correspondence
}

functionalities of biomolecules. ${ }^{18,19}$ There are several reports of supramolecular architectures of organic or inorganic-organic hybrid systems, where $\pi-\pi$ interactions and cation- $\pi$ interactions play crucial roles in directing the solid-state structure..$^{18-23}$ On the contrary, the concept of anion- $\pi$ interactions ${ }^{12,24-28}$ or the lonepair- $\pi$ interaction ${ }^{12,29-31}$ is much less intuitive, since this type of interaction between an electron donor and a $\pi$-aromatic cloud is expected to be repulsive. ${ }^{32-36}$ This may be the probable reason for a small literature on anion- $\pi$ interactions. B P Hay et al. showed in a recent perspective through an in-depth analysis that anion- $\pi$ interaction is extremely rare with charge-neutral $\pi$ systems. ${ }^{36}$ Recently, enormous efforts have been paid to recognize anions, ${ }^{37-40}$ but suitable hosts which can recognize anions by $\pi$ interaction are still rare. ${ }^{14,15}$

Here we wish to present the synthesis and single crystal $\mathrm{x}$-ray structure of two compounds $\left[\mathrm{Mn}_{2}(2,4-\text { pyrdc })_{2}(\right.$ bpe $\left.)\left(\mathrm{H}_{2} \mathrm{O}\right)_{6}\right] \cdot 2 \mathrm{H}_{2} \mathrm{O}(\mathbf{1})$ and $\left[\mathrm{Zn}_{2}(2,4-\right.$ pyrdc $)_{2}$ (azpy) $\left.\left(\mathrm{H}_{2} \mathrm{O}\right)_{6}\right] \cdot 2 \mathrm{H}_{2} \mathrm{O}$ (2) $[2,4$-pyrdc $=2,4-$ pyridinedicarboxylate; bpe $=1,2$ bis(4-pyridyl)ethane; azpy $=4,4^{\prime}$ azobipyridine] that are dinuclear molecular entities, extended to 3D by non-covalent interactions. In 
the stabilization of these supramolecular frameworks, carboxylate $(\mathrm{O}) \ldots \pi$ interactions, which can be treated as a combination of unusual anion- $\pi$ interactions ${ }^{12,24-28}$ as well as the lone-pair- $\pi$ interaction; ${ }^{12,29-31}$ might have played a crucial role. In the solid-state structure of $\mathbf{1}$, the carboxylate $(\mathrm{O}) \ldots \pi$ interactions make $3 \mathrm{D}$ supramolecular architecture whereas in 2 that interaction can extend up to 2D. Moreover, this diversity in supramolecular structures is achieved by another weak force like C-H. . $\pi$ interaction. ${ }^{41-43}$ To the best of our knowledge, these are very rare examples where an interplay of carboxylate $(\mathrm{O}) \ldots \pi$ interaction and $\mathrm{C}-\mathrm{H} . \ldots \pi$ interactions are responsible for the organization of supramolecular structure. Furthermore, several $(\mathrm{O}-\mathrm{H} . . . \mathrm{O}$ and $\mathrm{O}-\mathrm{H} . . . \mathrm{N}) \mathrm{H}$-bonding interactions in $\mathbf{1}$ and 2 also helped in the stabilization of these supramolecular structures.

\section{Experimental}

\subsection{Materials}

All the reagents and solvents employed were commercially available and used as supplied without further purification. $\mathrm{MnCl}_{2} \cdot 4 \mathrm{H}_{2} \mathrm{O}, \mathrm{Zn}\left(\mathrm{NO}_{3}\right)_{2} \cdot 6 \mathrm{H}_{2} \mathrm{O}, 1,2-$ bis(4-pyridyl)ethane and 2,4-pyridinedicarboxylic acid were obtained from the Aldrich Chemical Co. 4, 4'azopyridine was synthesized according to the reported procedure.

\subsection{Synthesis of compounds}

The light yellow (for 1) and deep red (for 2) blockshaped single crystals were synthesized in $\mathrm{H}_{2} \mathrm{O} / \mathrm{MeOH}$ media by the reaction of $\mathrm{MnCl}_{2}$, bpe and 2,4-pyrdc and $\mathrm{Zn}\left(\mathrm{NO}_{3}\right)_{2}$, azpy and 2,4-pyrdc for $\mathbf{1}$ and $\mathbf{2}$, respectively.

2.2a Synthesis of $\left[\mathrm{Mn}_{2}(2,4-p y r d c)_{2}(\right.$ bpe $\left.)\left(\mathrm{H}_{2} \mathrm{O}\right)_{6}\right] \cdot 2 \mathrm{H}_{2}$ $O(1)$ : An aqueous solution (15 mL) of $\mathrm{MnCl}_{2} \cdot 4 \mathrm{H}_{2} \mathrm{O}$ ( $1 \mathrm{mmol}, 0.198 \mathrm{~g}$ ) was added dropwise to an aqueous solution $(5 \mathrm{~mL})$ of disodium salt of 2,4-pyridinedicarboxylic acid ( $1 \mathrm{mmol}, 0.229 \mathrm{~g})$ with constant stirring. Then a methanolic solution $(5 \mathrm{~mL})$ of bpe $(0.5 \mathrm{mmol} ; 0.092 \mathrm{~g})$ was slowly poured into the above reaction mixture. Then the whole reaction mixture was stirred for $2 \mathrm{~h}$ and a yellowish-white compound separated out. Then the reaction mixture was filtered and yellowish white precipitate was discarded and filtrate was kept for slow evaporation. Light yellowish square shaped crystals were formed after one week at ambient condition, which were separated and washed with $\mathrm{H}_{2} \mathrm{O}$. (Yield: 75\%). IR (KBr, cm $\left.{ }^{-1}\right)$; 3424 br, $3151 \mathrm{w}, 3070 \mathrm{w}$,
1658 m, 1604 m, 1556 m, 1392 s, 1091 s, 890 s. Anal. calcd. for $\mathrm{C}_{26} \mathrm{H}_{34} \mathrm{Mn}_{2} \mathrm{~N}_{4} \mathrm{O}_{16}$ : C, 40.60; H, 4.42; N, 7.28. Found: C, 40.79; H, 4.27; N, 7.45\%.

$2.2 \mathrm{~b}$ Synthesis of $\left[\mathrm{Zn}_{2}(2,4-p y r d c)_{2}(\right.$ azpy $\left.)\left(\mathrm{H}_{2} \mathrm{O}\right)_{6}\right] \cdot 2 \mathrm{H}_{2}$ $O$ (2): Compound 2 was synthesized by adopting the similar procedure as that of compound 1. $\mathrm{Zn}$ $\left(\mathrm{NO}_{3}\right)_{2} \cdot 6 \mathrm{H}_{2} \mathrm{O}$ and azpy were used instead of $\mathrm{MnCl}_{2} \cdot 4 \mathrm{H}_{2} \mathrm{O}$ and bpe, respectively. Deep red square shaped crystals were obtained after two weeks at ambient condition, which were separated and washed with $\mathrm{H}_{2} \mathrm{O}$ (Yield: 85\%). IR (KBr, $\left.\mathrm{cm}^{-1}\right) ; 3424$ br, $3151 \mathrm{w}$, $3070 \mathrm{w}, 1658 \mathrm{~m}, 1604 \mathrm{~m}, 1556 \mathrm{~m}, 1392 \mathrm{~s}, 1091 \mathrm{~s}, 890$ s. Anal. calcd. for $\mathrm{C}_{24} \mathrm{H}_{30} \mathrm{~N}_{6} \mathrm{O}_{16} \mathrm{Zn}_{2}$ : C, 36.48; H, 3.80; N, 10.64. Found: C, 36.56; H, 3.59; N, $10.51 \%$.

\subsection{Physical measurement}

The elemental analyses were carried out using a Perkin Elmer $2400 \mathrm{CHN}$ analyzer. IR spectra of both the compounds were recorded on a Bruker IFS 66v/S spectrophotometer using the $\mathrm{KBr}$ pellets in the region 4000 $400 \mathrm{~cm}^{-1}$. The magnetic measurement were carried out on a crystalline sample $(\sim 15 \mathrm{mg})$ of $\mathbf{1}$ with a quantum design MPMS SQUID magnetometer (applied field 1T) working in the temperature range $2-300 \mathrm{~K}$. Correction for the sample holder was made by previous calibration and diamagnetic corrections were made from Pascal's table. ${ }^{44}$

\section{$2.4 \quad X$-ray crystallography}

For both the compounds, a suitable single crystal was mounted on a glass fiber and coated with epoxy resin. $\mathrm{X}$-ray data collection was carried out on a Rigaku Mercury diffractometer with graphite monochromated Mo$\mathrm{K}_{\alpha}$ radiation $(\lambda=0.71069 \AA)$ and a CCD $2 \mathrm{D}$ detector. The size of the unit cell was calculated from the reflections collected on the setting angles of seven frames by changing of $0.5^{\circ}$ for each frame. Three different settings were used and were changed by $0.5^{\circ}$ per frame and intensity data were collected with a scan width of $0.5^{\circ}$. Empirical absorption correction by using REQABA ${ }^{45}$ was performed for both complexes. The structures were solved by direct methods by using the SIR-92 program ${ }^{46}$ and expanded by using Fourier techniques. ${ }^{47}$ For 1, calculations were carried out using SHELXL 97, ${ }^{48}$ SHELXS $97,{ }^{49}$ PLATON $^{50}$ and WinGX system, Ver $1.70 .01 .^{51}$ Whereas for $\mathbf{2}$, it was performed using the teXsan crystallographic software package from Molecular Structure Corp. ${ }^{52}$ and PLATON. ${ }^{50}$ In both 
the cases hydrogen atoms could be located in the difference Fourier map and could be included in the final refinement. All the non-hydrogen atoms in both cases were refined anisotropically. Final refinement included atomic positions for all the atoms, anisotropic thermal parameters for all the non-hydrogen atoms, isotropic thermal parameters for the hydrogen atoms. Crystallographic and structure refinements parameters for $\mathbf{1}$ and $\mathbf{2}$ are given in table 1. Selected bond lengths, angles, $\mathrm{H}-$ bonding parameters for both the compounds (1 and $\mathbf{2}$ ) are reported in tables 2-5.

\section{Results and discussion}

\subsection{Structural description of 1}

Compound 1 crystallizes in triclinic $P^{\overline{1}}$ space group (table 1) and structure determination reveals that a dimeric molecular complex of $\mathrm{Mn}^{\mathrm{II}}$ comprised 2,4pyrdc, bpe and water molecules. Mn1 atom is connected to its symmetry related counterparts through the bpe linker forming a dinuclear molecular entity, $\left[\mathrm{Mn}_{2}(2,4-\right.$ pyrdc $)_{2}($ bpe $)\left(\mathrm{H}_{2} \mathrm{O}\right)_{6}$ ] (figure 1a). Each octahedral $\mathrm{Mn}^{\mathrm{II}}$ is chelated to one 2,4-pyrdc through $\mathrm{N} 1$ and $\mathrm{O} 4$ atoms, coordinated to three water molecules $(\mathrm{O} 1, \mathrm{O} 2$ and $\mathrm{O} 3)$ and one nitrogen $(\mathrm{N} 2)$ atom from the bpe linker forming the $\mathrm{MnN}_{2} \mathrm{O}_{4}$ chromophore. $\mathrm{Mn} 1-\mathrm{O}$ and $\mathrm{Mn} 1-\mathrm{N}$ bond distances are in the range of 2.1487(15)-2.1921(16) and 2.2210(14)-2.2717(14) A, respectively (table 2). Separation between two $\mathrm{Mn}^{\mathrm{II}}$ centres through the bpe linker is about $13.495 \AA$. The non-coordinating pendant carboxylate groups of 2,4-pyrdc in the dinuclear entity play a crucial role in the formation of the supramolecular structure. Each dinuclear entity undergoes $\mathrm{H}$ bonding (O5...O2, O4 ..O3) along the $a$-axis forming a $1 \mathrm{D}$ chain structure (figure $2 \mathrm{a}$, table 3 ). 1D chains are further connected by the $\mathrm{O} 7$...O1 H-bonding interactions forming a 2D sheet, lying on the face diagonal of the crystallographic $a b$ plane (figure 3 (marked area)). The 2D sheet undergoes further H-bonding interactions mediated by the crystalline water molecule $(\mathrm{O} 8, \mathrm{O} 1-$ O8-O7) resulting in a 3D supramolecular framework (figure 3, table 3). Mn...Mn separation along the 1D chain is $6.163 \AA$ and in the $2 \mathrm{D}$ sheet is about $7.352 \AA$. Apart from H-bonding, the free carboxylate oxygen atoms $(\mathrm{O} 6, \mathrm{O} 7)$ are involved in a mutual interaction with the $\pi$ electrons of pyridine rings of adjacent dimers (table 6), which further stabilizes the supramolecular structure (figure 4). There is also C-H. . . $\pi$ interaction between the $\mathrm{H}$ atom of bpe (H14) and the pyridine ring of 2,4-pyrdc (table 6), which facilitates the orientation of the dimeric fragment in such a way that it not

Table 1. Crystallographic data and structure refinement parameters for $\mathbf{1}$ and $\mathbf{2}$.

\begin{tabular}{lcc}
\hline Complex & $\mathbf{1}$ & $\mathbf{2}$ \\
\hline Empirical formula & $\mathrm{C}_{26} \mathrm{H}_{34} \mathrm{~N}_{4} \mathrm{O}_{16} \mathrm{Mn}_{2}$ & $\mathrm{C}_{24} \mathrm{H}_{30} \mathrm{~N}_{6} \mathrm{O}_{16} \mathrm{Zn}_{2}$ \\
Molecular weight & 768.45 & 789.29 \\
Crystal system & Triclinic & Triclinic \\
Space group & $P \overline{1}$ & $P \overline{1}$ \\
$a(\AA)$ & $6.1628(9)$ & $6.047(3)$ \\
$b(\AA)$ & $11.4705(18)$ & $11.635(3)$ \\
$c(\AA)$ & $12.3489(17)$ & $11.7480(10)$ \\
$\alpha\left({ }^{\circ}\right)$ & $75.303(10)$ & $74.01(10)$ \\
$\beta\left({ }^{\circ}\right)$ & $71.520(9)$ & $78.580(10)$ \\
$\gamma\left({ }^{\circ}\right)$ & $76.816(11)$ & $73.61(6)$ \\
$V\left(\AA^{3}\right)$ & $790.4(2)$ & $755.8(6)$ \\
$Z$ & 1 & 1 \\
$T(\mathrm{~K})$ & 293 & 293 \\
$\lambda(\mathrm{Mo} \mathrm{K})$ & 0.71069 & 0.71069 \\
$D_{\text {calc }}\left(\mathrm{g} \mathrm{cm}^{-3}\right)$ & 1.614 & 1.725 \\
$\mu\left(\mathrm{mm}^{-1}\right)$ & 0.880 & 1.674 \\
$\theta_{\text {max }}\left({ }^{\circ}\right)$ & 27.1 & 31.0 \\
$F(000)$ & 396 & 400 \\
Total data & 2834 & 7035 \\
Data $[I>2 \sigma(I)]$ & 2564 & 2780 \\
$R^{\mathrm{a}}$ & 0.0351 & 0.0425 \\
$R_{\mathrm{w}}^{\mathrm{b}}$ & 0.0958 & 0.0563 \\
$\mathrm{GOF}$ & 1.05 & 0.85 \\
\hline
\end{tabular}

${ }^{\mathrm{a}} \mathrm{R}=\sum\left\|\mathrm{F}_{\mathrm{o}}|-| \mathrm{F}_{\mathrm{c}}\right\| / \sum\left|\mathrm{F}_{\mathrm{o}}\right| ;{ }^{\mathrm{b}} \mathrm{R}_{\mathrm{w}}=\left[\sum\left\{\mathrm{w}\left(\mathrm{F}_{\mathrm{o}}^{2}-\mathrm{F}_{\mathrm{c}}^{2}\right)^{2}\right\} / \sum\left\{\mathrm{w}\left(\mathrm{F}_{\mathrm{o}}^{2}\right)^{2}\right\}\right]^{1 / 2}$ 
Table 2. Selected bond lengths $(\AA)$ and angles $\left(^{\circ}\right)$ for $\mathbf{1}$.

\begin{tabular}{lccc}
\hline Mn1-O1 & $2.1698(15)$ & Mn1-O2 & $2.1921(16)$ \\
Mn1-O3 & $2.1487(15)$ & Mn1-O4 & $2.1888(14)$ \\
Mn1-N1 & $2.2717(14)$ & Mn1-N2 & $2.2210(14)$ \\
O1-Mn1-O2 & $172.56(7)$ & O1-Mn1-O3 & $88.69(6)$ \\
O1-Mn1-O4 & $94.12(6)$ & O1-Mn1-N1 & $88.99(5)$ \\
O1-Mn1-N2 & $86.27(5)$ & O2-Mn1-O3 & $85.00(6)$ \\
O2-Mn1-O4 & $92.66(6)$ & O2-Mn1-N1 & $95.81(6)$ \\
O2-Mn1-N2 & $90.83(6)$ & O3-Mn1-O4 & $171.93(6)$ \\
O3-Mn1-N1 & $98.32(6)$ & O3-Mn1-N2 & $98.99(6)$ \\
O4-Mn1-N1 & $74.20(5)$ & O4-Mn1-N2 & $88.76(5)$ \\
N1-Mn1-N2 & $161.93(5)$ & & \\
\hline
\end{tabular}

Table 3. Hydrogen Bonding parameters $\left(\AA{ }^{\circ}\right)$ for $\mathbf{1}$.

\begin{tabular}{|c|c|c|c|c|}
\hline D-H...A & D-H & H...A & D...A & $<$ D-H..A $>$ \\
\hline O1-H1..O8 ${ }^{\mathrm{i}}$ & $0.77(2)$ & $2.06(2)$ & $2.828(2)$ & 174(3) \\
\hline $\mathrm{O} 1-\mathrm{H} 2 \ldots \mathrm{O}^{\mathrm{ii}}$ & $0.79(3)$ & $1.89(3)$ & $2.650(2)$ & $164(3)$ \\
\hline $\mathrm{O} 2-\mathrm{H} 3 . . \mathrm{O} 4^{\mathrm{iii}}$ & $0.75(3)$ & $2.19(3)$ & $2.934(2)$ & $170(3)$ \\
\hline $\mathrm{O} 2-\mathrm{H} 4$..O5 ${ }^{\mathrm{iv}}$ & $0.79(4)$ & $1.97(4)$ & $2.733(2)$ & 161(3) \\
\hline $\mathrm{O} 3-\mathrm{H} 5 . . \mathrm{O} 4^{\mathrm{iv}}$ & $0.91(3)$ & $2.07(3)$ & $2.951(2)$ & $162(2)$ \\
\hline O3- H6.. O8 & $0.86(3)$ & $1.81(3)$ & $2.663(2)$ & $178.0(12)$ \\
\hline $\mathrm{O} 8-\mathrm{H} 16 . . \mathrm{O}^{\mathrm{v}}$ & $0.82(4)$ & $1.95(4)$ & $2.767(3)$ & 171(4) \\
\hline O8- H17.. O6 ${ }^{\mathrm{ii}}$ & $0.88(3)$ & $1.83(3)$ & $2.667(2)$ & $159(3)$ \\
\hline
\end{tabular}

Symmetry code: $\mathrm{i}=1-\mathrm{x}, 2-\mathrm{y}, 2-\mathrm{z} ; \mathrm{ii}=2-\mathrm{x}, 1-\mathrm{y}, 2-\mathrm{z}$; iii $=2-\mathrm{x}, 2-\mathrm{y}$, $1-\mathrm{z} ; \mathrm{iv}=-1+\mathrm{x}, \mathrm{y}, \mathrm{z} ; \mathrm{v}=1-\mathrm{x}, 1-\mathrm{y}, 2-\mathrm{z} ; \mathrm{vi}=-1+\mathrm{x}, 1+\mathrm{y}, \mathrm{z}$

Table 4. Selected bond lengths $(\AA)$ and angles $\left({ }^{\circ}\right)$ for $\mathbf{2}$.

\begin{tabular}{lccc}
\hline Zn1-O1 & $2.144(4)$ & Zn1-O2 & $2.079(4)$ \\
Zn1-O3 & $2.075(3)$ & Zn1-O4 & $2.113(3)$ \\
Zn1-N1 & $2.140(4)$ & Zn1-N2 & $2.117(4)$ \\
N1-Zn1-N2 & $166.97(18)$ & O1-Zn1-O3 & $86.03(16)$ \\
O1-Zn1-O2 & $176.31(16)$ & O1-Zn1-N1 & $89.73(17)$ \\
O1-Zn1-O4 & $90.43(15)$ & O2-Zn1-O3 & $90.29(16)$ \\
O1-Zn1-N2 & $91.75(17$ & O2-Zn1-N1 & $90.51(17)$ \\
O2-Zn1-O4 & $93.22(15)$ & O3-Zn1-O4 & $174.71(15)$ \\
O2-Zn1-N2 & $88.84(17)$ & O3-Zn1-N2 & $94.88(17)$ \\
O3-Zn1-N1 & $98.14(17)$ & O4-Zn1-N2 & $89.15(16)$ \\
O4-Zn1-N1 & $77.90(16)$ & & \\
\hline
\end{tabular}

Table 5. Hydrogen bonding parameters $\left(\AA{ }^{\circ}{ }^{\circ}\right)$ for 2 .

\begin{tabular}{|c|c|c|c|c|}
\hline D-H...A & $\mathrm{D}-\mathrm{H}$ & H...A & D...A & $<$ D-H..A $>$ \\
\hline $\mathrm{O} 3-\mathrm{H} 12 . .08^{\mathrm{i}}$ & 0.9500 & 1.8900 & $2.679(5)$ & 139.00 \\
\hline $\mathrm{O} 3-\mathrm{H} 13 . . \mathrm{O} 4^{\mathrm{ii}}$ & 0.9500 & 1.9800 & $2.896(5$ & 161.00 \\
\hline $\mathrm{O} 2-\mathrm{H} 16 . . \mathrm{O} 8^{\mathrm{iii}}$ & 0.9500 & 2.5500 & $3.421(5)$ & 153.00 \\
\hline $\mathrm{O} 2-\mathrm{H} 17 . . \mathrm{O}^{\mathrm{iv}}$ & 0.9500 & 2.4300 & $2.764(5)$ & 100.00 \\
\hline $\mathrm{O} 1-\mathrm{H} 18 . . \mathrm{O} 4^{\mathrm{v}}$ & 0.9500 & 2.5100 & $2.897(4)$ & 105.00 \\
\hline $\mathrm{O} 1-\mathrm{H} 18 . . \mathrm{N} 2^{\mathrm{v}}$ & 0.9500 & 2.3900 & $3.321(5)$ & 168.00 \\
\hline $\mathrm{O} 1-\mathrm{H} 19 . . \mathrm{O} 4^{\mathrm{ii}}$ & 0.9500 & 2.5300 & $3.377(5)$ & 149.00 \\
\hline
\end{tabular}

Symmetry code: $\mathrm{i}=-1+\mathrm{x}, \mathrm{y},-1+\mathrm{z} ; \mathrm{ii}=-1+\mathrm{x}, \mathrm{y}, \mathrm{z}$; iii $=\mathrm{x}, \mathrm{y},-1+\mathrm{z}$; iv $=\mathrm{x}$, $-y, 1-z, \mathrm{v}=-\mathrm{x},-\mathrm{y}, 1-\mathrm{z}$. 

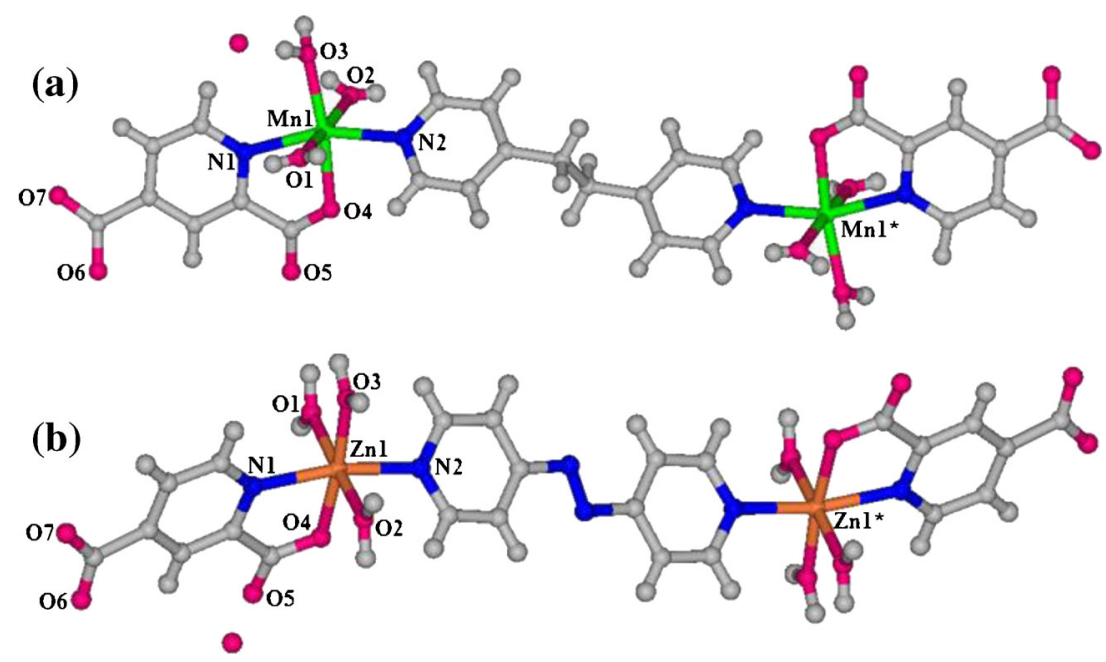

Figure 1. Dimeric fragment of (a) $\left[\mathrm{Mn}_{2}(2,4-\text { pyrdc })_{2}(\right.$ bpe $\left.)\left(\mathrm{H}_{2} \mathrm{O}\right)_{6}\right] \cdot 2 \mathrm{H}_{2} \mathrm{O}$ (1) and (b) $\left[\mathrm{Zn}_{2}(2,4-\text { pyrdc })_{2}\right.$ (azpy) $\left.\left(\mathrm{H}_{2} \mathrm{O}\right)_{6}\right] \cdot 2 \mathrm{H}_{2} \mathrm{O}$ (2) (color code: $\mathrm{Mn}$; green, $\mathrm{Zn}$; brick red, C; grey, N; blue, O; pink).

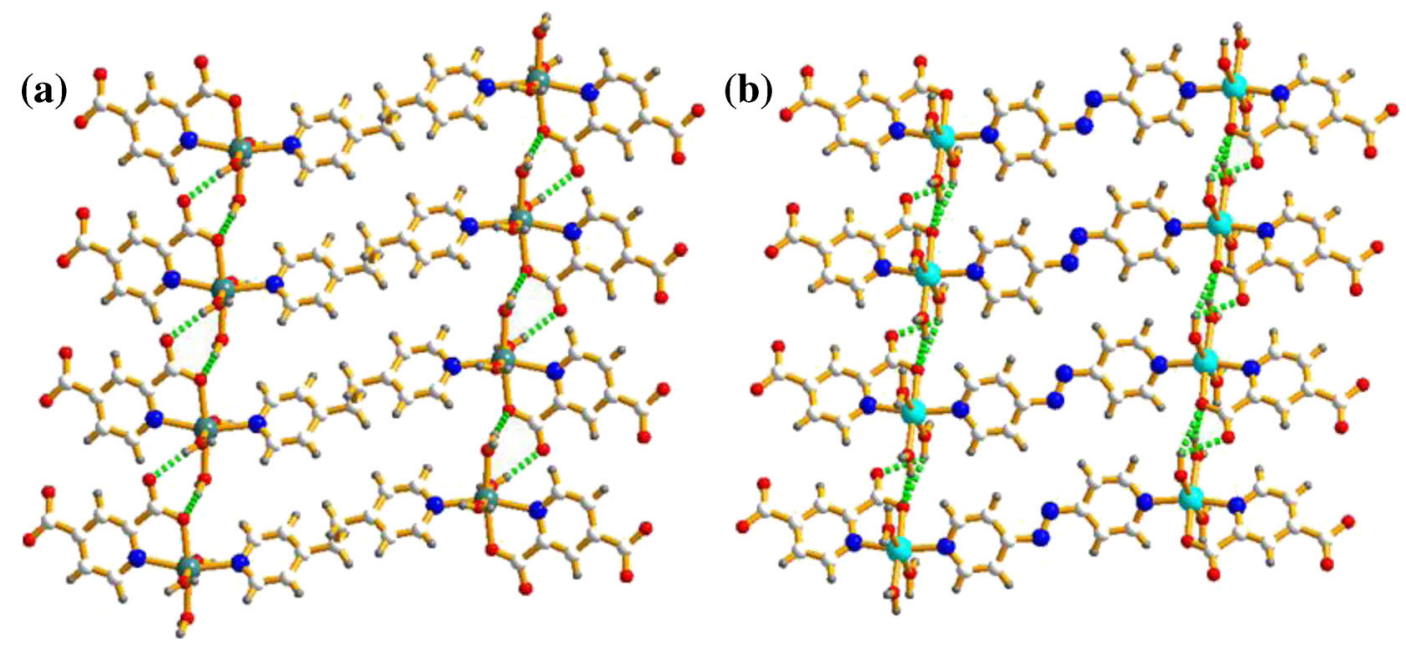

Figure 2. H-bonded 1D supramolecular array in (a) 1 and (b) $\mathbf{2}$ (color code: Mn; light green, Zn; cyan, C; white, N; blue, O; red, H; grey).

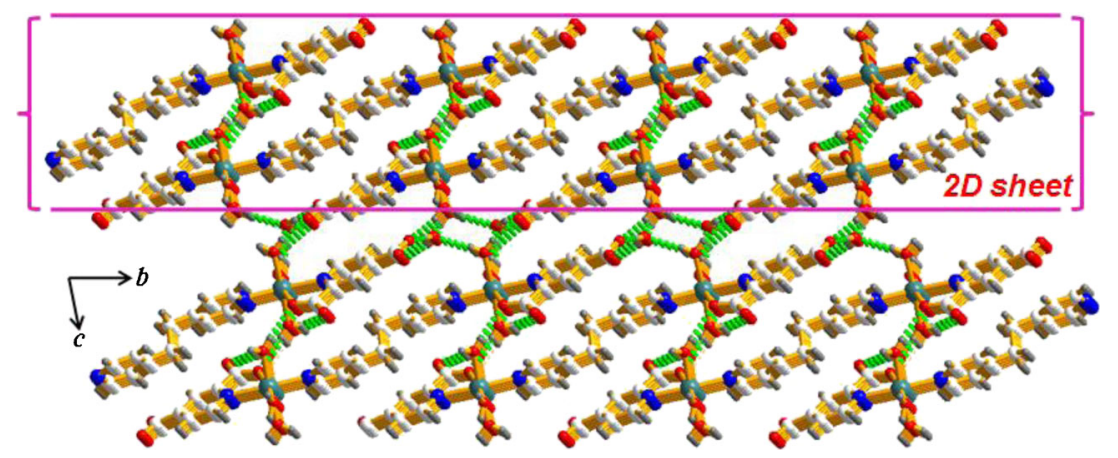

Figure 3. Supramolecular 3D continuum constructed by H-bonding in $\mathbf{1}$. 
Table 6. C-H... $\pi /$ Carboxylate- $\pi(\mathrm{O} \ldots \pi)$ Interactions for $\mathbf{1}$ and $\mathbf{2}$.

\begin{tabular}{cccccc}
\hline & $\mathrm{Y}-\mathrm{X}->\mathrm{R}(\mathrm{i})$ & $\perp$ distance of $\mathrm{X}-\mathrm{on} \mathrm{R}(i)[\AA]$ & $\mathrm{X} \ldots \mathrm{R},[\AA]$ & $<\mathrm{Y}-\mathrm{X} \ldots \mathrm{R},\left[^{\circ}\right]$ & $\mathrm{Y} \ldots \mathrm{R},[\AA]$ \\
\hline $\mathbf{1}^{\mathrm{a}}$ & $\mathrm{C}(13)-\mathrm{H}(14) \rightarrow \mathrm{R}(1)^{\mathrm{i}}$ & $2.78(5)$ & $2.79(3)$ & $159(3)$ & $3.723(2)$ \\
& $\mathrm{C}(5)-\mathrm{O}(6) \rightarrow \mathrm{R}(2)^{\mathrm{ii}}$ & $3.414(5)$ & $3.453(2)$ & $126.18(13)$ & $4.302(2)$ \\
& $\mathrm{C}(5)-\mathrm{O}(7) \rightarrow \mathrm{R}(1)^{\mathrm{iii}}$ & $3.506(5)$ & $3.5924(18)$ & $84.32(11)$ & $3.6853(19)$ \\
$2^{\mathrm{b}}$ & $\mathrm{C}(5)-\mathrm{O}(6) \rightarrow \mathrm{R}(2)^{\mathrm{i}}$ & 3.330 & 3.4043 & 142 & 4.4314 \\
& $\mathrm{C}(5)-\mathrm{O}(7) \rightarrow \mathrm{R}(1)^{\mathrm{ii}}$ & 3.424 & 3.5445 & 88 & 3.7249 \\
& $\mathrm{O}(1)-\mathrm{H}(18) \rightarrow \mathrm{R}(2)^{\mathrm{iii}}$ & 2.39 & 2.64 & 141 & 3.4335 \\
\hline
\end{tabular}

${ }^{a}$ Symmetry code: (i) $\mathrm{x}, 1+\mathrm{y}, \mathrm{z}$; (ii) $1+\mathrm{x},-1+\mathrm{y}, \mathrm{z}$; (iii) $2-\mathrm{x}, 1-\mathrm{y}, 2-\mathrm{z}$.

${ }^{\mathrm{b}}$ Symmetry code: (i) $\mathrm{x}, 1+\mathrm{y}, \mathrm{z}$; (ii) $-\mathrm{x}, 1-\mathrm{y},-\mathrm{z}$; (iii) $-\mathrm{x},-\mathrm{y}, 1-\mathrm{z}$.

$* \mathrm{Y}=\mathrm{C} / \mathrm{O} ; \mathrm{X}=\mathrm{H} / \mathrm{O}$ depending upon the type of interactions whereas $\mathrm{R}(i)$ denote the $i$-th rings of 2,4-pyrdc/bpe/azpy in 1 and 2: $\mathrm{R}(1)=\mathrm{N} 1 / \mathrm{C} 1 / \mathrm{C} 3 / \mathrm{C} 4 / \mathrm{C} 6 / \mathrm{C} 7 ; \mathrm{R}(2)=\mathrm{N} 2 / \mathrm{C} 8 / \mathrm{C} 9 / \mathrm{C} 10 / \mathrm{C} 11 / \mathrm{C} 12$.

only relates to the adjacent dimers to form a $2 \mathrm{D}$ sheet but is also extended into a 3D supramolecular entity. Figure 4 represents a part of the 2D sheets which shows the organization of carboxylate $(\mathrm{O}) \ldots \pi$ interactions in $\mathbf{1}$. When this supramolecular assembly is viewed along the $a$-axis, a rectangular $\pi$-directed channel is observed, occupied by the lattice water molecules (figure 5). Therefore, the dinuclear fragment acts as a building unit for the higher dimensional structure through non-covalent interactions where carboxylate $(\mathrm{O}) \ldots \pi$ interactions play a crucial role.

\subsection{Structural description of 2}

Compound $\mathbf{2}$ also crystallizes in triclinic $P \overline{1}$ space group (table 1) and structure determination reveals an almost similar structure as that of compound 1 (figure $1 \mathrm{~b}$ ), where dinuclear $\mathrm{Zn}^{\mathrm{II}}$ complex is bridged by the azpy organic linker instead of bpe. Each octahedral $\mathrm{Zn}^{\mathrm{II}}$ atom is connected to a one chelated 2,4-pyrdc (N1, O4), three water molecules $(\mathrm{O} 1, \mathrm{O} 2$ and $\mathrm{O} 3)$ and one

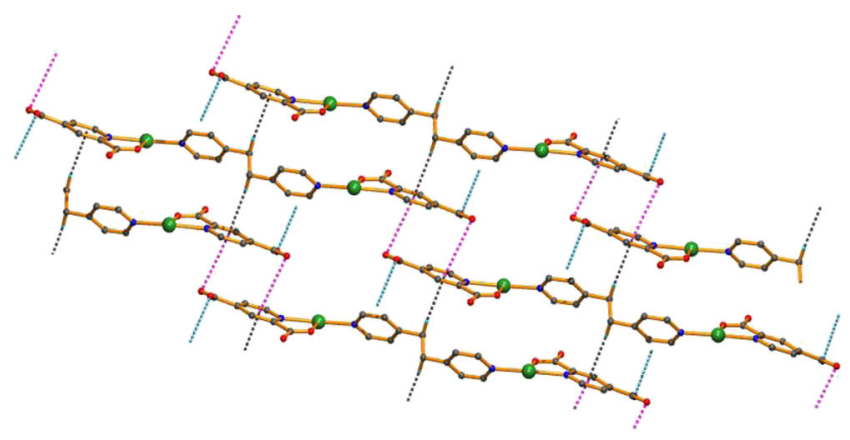

Figure 4. Carboxylate $(\mathrm{O}) \ldots \pi$ interaction and $\mathrm{C}-\mathrm{H} . \ldots \pi$ interactions in $\mathbf{1}$ (water molecules has been removed for clarity; magenta and sky blue dotted lines indicate the intra-sheet and inter-sheet $\mathrm{O} \ldots \pi$ interactions, respectively whereas the violet dotted line indicates $\mathrm{C}-\mathrm{H}$. . . $\pi$ interactions). nitrogen atom (N2) from the azpy linker forming the $\mathrm{ZnN}_{2} \mathrm{O}_{4}$ chromophore. $\mathrm{Zn1}$ atom is bridged with its symmetry related counterparts through the azpy linker at a distance of $13.115 \AA$. In the dinuclear fragment, $\mathrm{Zn} 1-\mathrm{O}$ and $\mathrm{Zn} 1-\mathrm{N}$ bond distances are in the range of

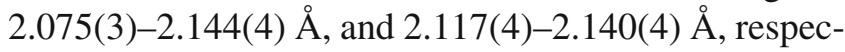
tively, which are slightly smaller than that of the Mn-O and $\mathrm{Mn}-\mathrm{N}$ bond distances in complex 1 (table 4). The degree of distortion from the ideal octahedral geometry is reflected in the cisoid and transoid angles that are

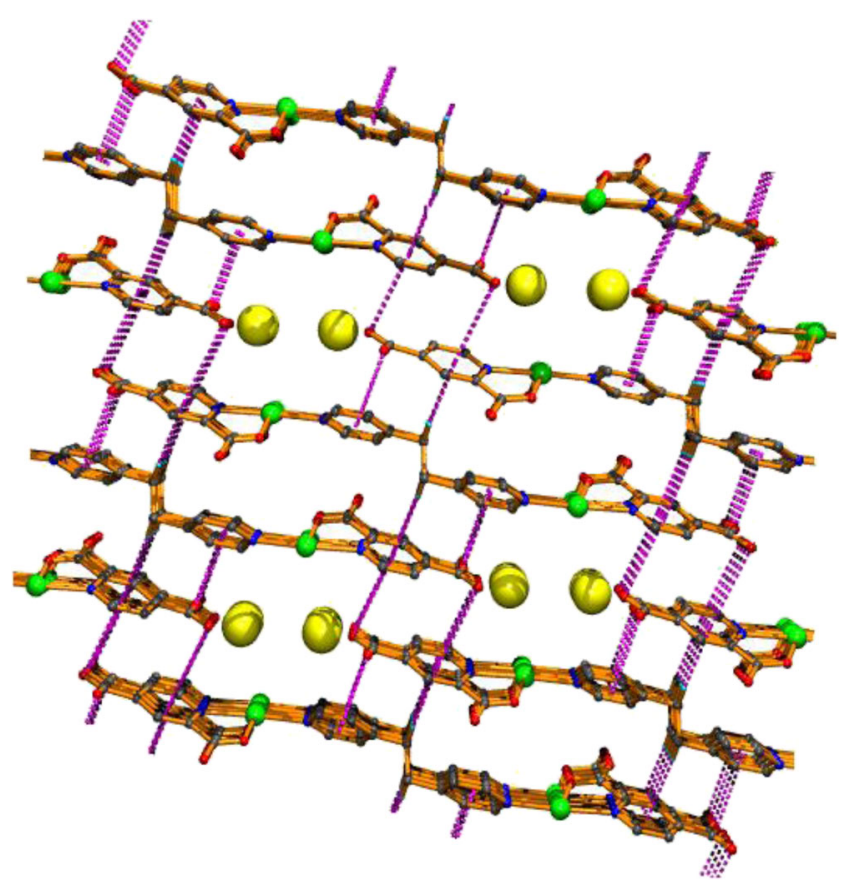

Figure 5. The $a$-axis projection of the 3D supramolecular continuum in 1 constructed by, carboxylate $(\mathrm{O}) \ldots \pi$ interaction and C-H. . . $\pi$ interactions (coordinated water molecules have been removed for clarity whereas $\mathrm{O}$ atom of lattice water molecules are shown as yellow balls; magenta dotted lines indicate both $\mathrm{O} \ldots \pi$ interactions and C-H... interaction). 
in the range of $77.90(16)-98.14(17)^{\circ}$ and 166.97(18)$176.31(16)^{\circ}$, respectively (table 4$)$. This is very common for an octahedral $\mathrm{d}^{10}$ system. The H-bonding patterns in $\mathbf{2}$ are almost similar to that of $\mathbf{1}$ (figure $2 b$, table 5). The dinuclear entities stack along the $a$-axis through $\mathrm{H}$-bonding interactions to form 1D chains which are further linked through $\mathrm{H}$-bonding to form an overall 3D supramolecular architecture (figure $2 \mathrm{~b}$ and 6 , table 5). Here in $\mathbf{2}$, one intra-molecular $\mathrm{O}-\mathrm{H} . . \pi$ interaction is present between the $\mathrm{H}$ atom of one of the coordinated water molecule and the nearest ring of azpy, which is not observed in case of $\mathbf{1}$ (table 6). Similar to that of $\mathbf{1}$, the free carboxylate oxygen atoms $(\mathrm{O} 6, \mathrm{O} 7)$ made a mutual interaction with the $\pi$ electrons of pyridine ring of adjacent dimers (table 6), and stabilized the supramolecular structure. But in $2 \mathrm{C}-\mathrm{H} . . . \pi$, interaction is not observed due to the modification of $-\mathrm{CH}_{2}-$ $\mathrm{CH}_{2}-$ to $-\mathrm{N}=\mathrm{N}-$ moiety in the ligand structure. The azpy is almost same in the length and geometry like bpe, but does not have the methyne hydrogen, which had taken part in the C-H. . $\pi$ interaction in the case of $\mathbf{1}$. Due to a lack of this $\mathrm{C}-\mathrm{H} . . \pi \pi$ interaction, the pyridine ring of 2,4-pyrdc are in a suitable orientation to interact with the adjacent dimers to form a $2 \mathrm{D}$ sheet only. Figure 7 represents a part of 2D sheets showing carboxylate $(\mathrm{O}) \ldots \pi$ interactions. The non-existence of $\mathrm{C}-\mathrm{H} . . \pi$ interactions probably help the pyridine rings of 2,4-pyrdc to interact through the sheet, which is unavailable in $\mathbf{1}$ due to the offset orientation for $\mathrm{C}-\mathrm{H} . . . \pi$ interactions.

\subsection{Magnetic property of $\mathbf{1}$ and magneto-structural correlations}

The temperature dependence (300-2 K) of $\chi_{M}, 1 / \chi_{M}$ and $\chi_{M} T$ for complex 1 is given in figure $8\left(\chi_{M}\right.$ is the magnetic susceptibility for two $\mathrm{Mn}^{\mathrm{II}}$ ion). The $\chi_{\mathrm{M}}$ value of 1 at $300 \mathrm{~K}$ is $0.03073 \mathrm{~cm}^{3} \mathrm{~mol}^{-1}\left(\chi_{\mathrm{M}} T=9.2276 \mathrm{~cm}^{3}\right.$ $\mathrm{mol}^{-1} \mathrm{~K}$ at $300 \mathrm{~K}$ ) and is in good agreement with the expected values for an isolated dimer of spin $\mathrm{S}=5 / 2$

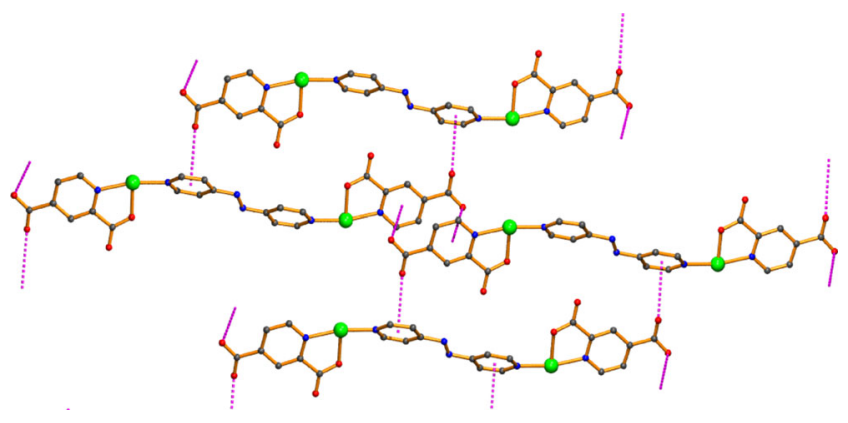

Figure 7. Carboxylate $(\mathrm{O}) \ldots \pi$ interaction and $\mathrm{C}-\mathrm{H} \ldots \pi$ interactions in $\mathbf{2}$ (water molecules have been removed for clarity; magenta dotted line indicates the intra-sheet $\mathrm{O} \ldots \pi$ interactions).

$\left(0.02913 \mathrm{~cm}^{3} \mathrm{~mol}^{-1}\right)$ system. ${ }^{44,53}$ With the decrease of temperature, the $\chi_{\mathrm{M}}$ value shows a smooth increase up to $30 \mathrm{~K}\left(0.26567 \mathrm{~cm}^{3} \mathrm{~mol}^{-1}\right)$ and then exhibits a sharp and steep increase upon further cooling and at $2 \mathrm{~K}$ the value being $3.03936 \mathrm{~cm}^{3} \mathrm{~mol}^{-1}$ (figure 8 ). The $\chi_{\mathrm{M}} T$ vs $T$ plot shows a gradual decrease in the value of $\chi_{M} \mathrm{~T}$ from $300-12 \mathrm{~K}$ and then a steep decrease in the value and finally at $2 \mathrm{~K}$ it becomes $6.0889 \mathrm{~cm}^{3} \mathrm{~mol}^{-1} \mathrm{~K}$ (figure 8 ). The shape of these curves is characteristic of the occurrence of weak antiferromagnetic interactions between the $\mathrm{Mn}(\mathrm{II})$ centre connected by the long bridging ligand. There is no maxima in the $\chi_{\mathrm{M}} v s \mathrm{~T}$ curve, indicating no long-range antiferromagnetic order, at least at $\mathrm{T}>2 \mathrm{~K}^{54}$ The $1 / \chi_{\mathrm{M}} v s \mathrm{~T}$ plot has good agreement with Currie-Weiss equation within the temperature range of 2 to $300 \mathrm{~K}$. The fitting of the Currie-Weiss equation $\left(1 / \chi_{\mathrm{M}}=(\mathrm{T}-\theta) / \mathrm{C}\right)$ provides the Curie's constant $\mathrm{C}=9.00333 \mathrm{~cm}^{3} \mathrm{~K} \mathrm{~mol}^{-1}$ (for dimeric unit) and $\theta=-2.94 \mathrm{~K}$ (figure 8 ). The nature of the $\chi_{\mathrm{M}}$ vs T plot and $\chi_{\mathrm{M}} T$ vs T plot and the negative $\theta$ value are suggesting that there is an antiferromagnetic interaction between the $\mathrm{Mn}(\mathrm{II})$ centres connected by a long bridging ligand. ${ }^{44}$

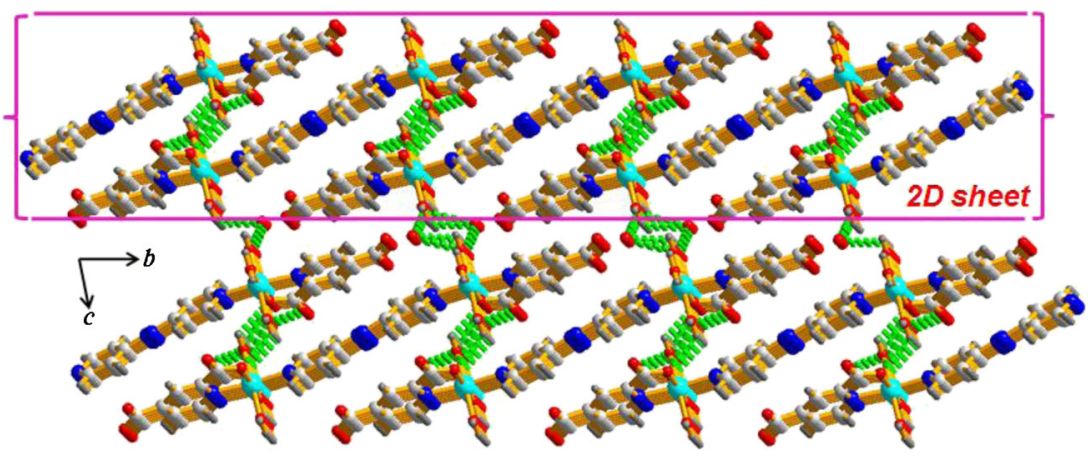

Figure 6. Supramolecular $3 \mathrm{D}$ continuum constructed by H-bonding in 2 . 


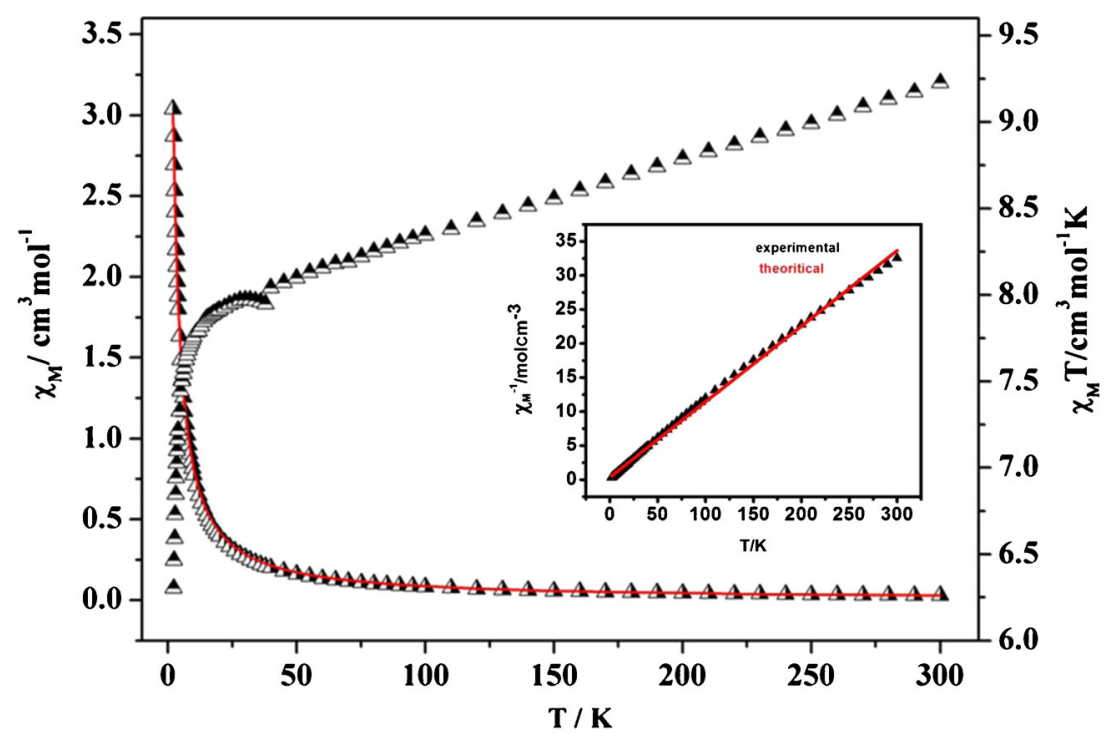

Figure 8. The plots of $\chi_{M}$ and $\chi_{M} T$ vs $T$ for 1 . Inset: The plot of $1 / \chi_{M}$ vs $T$ for 1 . The red lines indicate the best fit obtained.

In spite of the high metal-metal distance through

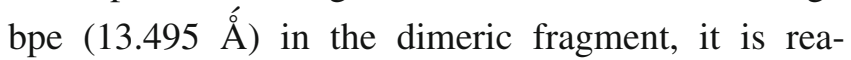
sonable to analyse the molar magnetic susceptibility data for the dinuclear cation assuming very weak electronic exchange between the $\mathrm{Mn}^{\mathrm{II}}$ centers. Assuming the isotropic exchange, the exchange Hamiltonian is $H=-2 J S_{1} \cdot S_{2}$ with $S_{1} S_{2}=5 / 2$ and the magnetic susceptibility per cation is given by the equation $(1)^{55}$ where $N, g, \beta, k$ are the Avogadro number, $g$ factor, Bohr magneton and Boltzman constant, respectively. Here $x=\exp (-\mathrm{J} / \mathrm{kT})$ and $J$ is the exchange coupling constant for the dinuclear cation.

$$
\chi_{M}=\frac{2 N g^{2} \beta^{2}}{k T}\left[\frac{55+30 x^{2}+14 x^{18}+5 x^{24}+x^{28}}{11+9 x^{10}+7 x^{18}+5 x^{24}+3 x^{28}+x^{30}}\right]
$$

The best fit parameters are given by the superexchange parameter, $J=-0.078 \mathrm{~cm}^{-1}, g=1.99$ and the discrepancy factor $\mathrm{R}=5.2 \times 10^{-4}$ which is defined as $\left\{\sum\left[\left(\chi_{\mathrm{M}}\right)_{\mathrm{obs}}-\left(\chi_{\mathrm{M}}\right)_{\mathrm{calc}}\right]^{2} / \sum\left(\chi_{\mathrm{M}}\right)_{\mathrm{obs}}^{2}\right\}$ (figure 8). This very small $J$ value is due to the weakly coupled $\mathrm{Mn}^{\mathrm{II}}$ centres in the complex $\mathbf{1}$ and which is comparable with those reported for divalent $\mathrm{Mn}$ (II) systems connected by a long bridging ligand. ${ }^{53,56-58}$

\section{Conclusion}

The physical viability of forming anion- $\pi$ interaction is less, as the order of stability in the interactions of two $\pi$ systems is $\pi$-deficient- $\pi$-deficient $>\pi$-deficient$\pi$-rich $>\pi$-rich- $\pi$-rich. ${ }^{34}$ But sometimes these interactions may be useful in directing the supramolecular structures along with other cooperative weak interac- tions. Here we showed the crystallographic evidence of existence of rare carboxylate $(\mathrm{O})$ - $\pi$ interactions, which acts to propagate the dimeric fragments into extended supramolecular architectures. Moreover, it is important to note that the $\mathrm{C}-\mathrm{H} . \ldots \pi$ interactions here played a crucial role in controlling the carboxylate $(\mathrm{O})-\pi$ interactions, which is achieved by a simple modulation of the structure of the organic linker. At the threshold of our understanding in supramolecular interactions, it is possible to speculate such an inter-relation between weakly driven forces, which are the driving force for developing supramolecular architectures. This can be achieved by modulating the coordination structure or simply by modifying a part of it.

\section{Supplementary Information}

CCDC 752075 and 752076 contain the supplementary crystallographic data for $\mathbf{1}$ and $\mathbf{2}$, respectively. These data can be obtained free of charge from The Cambridge Crystallographic Data Centre.

\section{Acknowledgements}

S M and S R thank UGC for fellowship. D G thanks JNCASR for visiting fellowship programme. T K M thanks DST, Government of India, for the financial support (fast track proposal).

\section{References}

1. Batten S R and Robson R 1998 Angew. Chem., Int. Ed. 371461

2. Moulton B and Zaworotko M J 2001 Chem. Rev. 101 1629 
3. Janiak C 2003 Dalton Trans. 2781

4. Yaghi O M, O'Keeffe M, Ockwig N W, Chae H K, Eddaoudi M and Kim J 2003 Nature 423705

5. Kitagawa S, Kitaura R and Noro S-I 2004 Angew. Chem. Int. Ed. 432334

6. AakerÖy C, Champness $\mathrm{N}$ and Janiak C 2010 Cryst. Eng. Comm. 1222

7. Férey G 2009 Dalton Trans. 4400

8. Desiraju G R 1996 Acc. Chem. Res. 29441

9. Garau C, Quiñonero D, Frontera A, Escudero D, Ballester P, Costa A and Deyà P M 2007 Chem. Phys. Lett. 438104

10. Mascal M 2006 Angew. Chem. Int. Ed. 452890

11. Ghoshal D, Ghosh A K, Ribas J, Mostafa G and Ray Chaudhuri N 2005 Cryst. Eng. Comm. 7616

12. Biswas C, Drew M G B, Escudero D, Frontera A and Ghosh A 2009 Eur. J. Inorg. Chem. 2238

13. Vilar R 2003 Angew. Chem., Int. Ed 421460

14. Quiňonero D, Garau C, Rotger C, Frontera A, Ballester P, Costa A and Deyà P M 2002 Angew. Chem. Int. Ed. 413389

15. de Hoog P, Gamez P, Mutikainen I, Turpeinen U and Reedijk J 2004 Angew. Chem. Int. Ed. 435815

16. Meyer E A, Castellano R K and Diederich F 2003 Angew. Chem., Int. Ed. 421210

17. Egli M, Tereshko V, Mushudov G N, Sanishvili R, Liu X Y and Lewis F D 2003 J. Am. Chem. Soc. 125108422

18. Gallivan J P and Dougherty D A 1999 Proc. Natl. Acad. Sci. U.S.A. 969459

19. Scrutton N S and Raine A R C 1996 Biochem. J. 3191

20. Lehn J-M 1995 Supramolecular chemistry. Concepts and perspectives (Weinheim: $\mathrm{VCH}$ )

21. Meyer EA, Castellano R K and Diederich F 2003 Angew. Chem. Int. Ed. 421210

22. Ghoshal D, Maji T K, Mostafa G, Sain S, Lu T-H, Ribas J, Zangrando E and Ray Chaudhuri N 2004 Dalton Trans. 1687

23. Ghosh A K, Ghoshal D, Lu T-H, Mostafa G and Ray Chaudhuri N 2004 Cryst. Growth Des. 4851

24. Gamez P, Mooibroek T J, Teat S J and Reedijk J 2007 Acc. Chem. Res. 40435

25. Götz R J, Robertazzi A, Mutikainen I, Turpeinen U, Gamez P and Reedijk J 2008 Chem. Commun. 293384

26. Schottel B L, Chifotides H T and Dunbar K R 2008 Chem. Soc. Rev. 3768

27. Hay B P and Bryantsev V S 2008 Chem. Commun. 29 2417

28. Kar P, Biswas R, Drew G B M, Frontera and Ghosh A 2012 Inorg. Chem. 511837

29. Egli M and Sarkhel S 2007 Acc. Chem. Res. 40197

30. Gao X-L, Lu L P and Zhu M-L 2009 Acta Cryst. C 65 123

31. Mooibroek T J, Gamez P and Reedijk J 2008 Cryst. Eng. Comm. 101501

32. Maspoch D, Ruiz-Molina D and Veciana J $2004 J$. Mater. Chem. 142713

33. Hunter C A and Sanders J K M 1990 J. Am. Chem. Soc. 1125525
34. Janiak C 2000 J. Chem. Soc., Dalton Trans. 3885

35. Hunter C A 1994 Chem. Soc. Rev. 23101

36. Hay B P and Custelcean R 2009 Cryst. Growth Des. 9 2539

37. Mangani S and Ferraroni M 1997 Supramolecular chemistry of anions (New York: Wiley)

38. Beer P D and Gale P 2001 Angew. Chem., Int. Ed. 40 487

39. Ghosh A K, Jana A D, Ghoshal D, Mostafa G and Ray Chaudhuri N 2006 Cryst. Growth Des. 6701

40. Lakshminarayanan P S, Ravikumar I, Suresh E and Ghosh P 2007 Inorg. Chem. 464769

41. Nishio M 2004 Cryst. Eng. Comm. 6130

42. Janiak C, Temizdemir S, Dechert S, Deck W, Girgsdies F, Heinze J, Kolm M J, Scharmann T G and Zipffel O M 2000 Eur. J. Inorg. Chem. 1229

43. Nishio M, Umezawa Y, Honda K, Tsuboyama S and Suezawa H 2009 Cryst. Eng. Comm. 111757

44. Khan O 1993 Molecular magnetism (New York: $\mathrm{VCH})$

45. Jacobson R A REQABA Empirical absorption correction Ver. 1.1-0310191998, Molecular Structure Corp., The Woodlands, TX, 1996-1998

46. Altomare A, Burla M C, Camalli M, Cascarano G L, Giacovazzo C, Guagliardi A, Moliterni A G G, Polidori G and Spagna R J 1999 Appl. Crystallogr. 32115

47. Beurskens P T, Admiraal G, Beurskens G, Bosman W P, deGelder R, Israel R and Smits J M M 1994 The DIRDIF-94 Program system: Technical report of the crystallography laboratory (Nijmegen, The Netherlands: University of Nijmegen)

48. Sheldrick G M 1997 SHELXL 97, Program for the solution of crystal structure (Germany: University of Gottingen)

49. Sheldrick G M 1997 SHELXS 97, Program for the refinement of crystal structure (Germany: University of Gottingen)

50. Spek A L 2003 PLATON, Molecular geometry program J. Appl. Crystallogr. 367

51. Farrugia L J 1999 WinGX - A windows program for crystal structure analysis J. Appl. Crystallogr. 32 837

52. TeXsan crystal structure analysis package 2000 (The Woodlands, TX: Molecular Structure Corp.)

53. Sain S, Maji T K, Mostafa G, Lu T-H and Ray Chaudhuri N 2003 Inorg. Chim. Acta 35112

54. Escuer A, Vicente R, Goher M A S and Mautner F A 1995 Inorg. Chem. 345707

55. Hatfield W E 1976 Theory and applications of molecular paramagnetism E A Boudreaus and L N Mulay (eds.) (New York: Wiley-Interscience) p. 349

56. Maji T K, Sain S, Mostafa G, Lu T-H, Ribas J, Monfort M and Ray Chaudhuri N 2003 Inorg. Chem. 42 709

57. Policar C, Lambert F, Cesario M and MorgensternBadarau I 1999 Eur. J. Inorg. Chem. 2201

58. Baldwin M J, Kampf J W, Kirk M L and Pecoraro V L 1995 Inorg. Chem. 345252 